\title{
GRUPOS VIVENCIAIS SOB UMA PERSPECTIVA JUNGUIANA
}

\author{
Laura Villares de Freitas 1 \\ Instituto de Psicologia - USP \\ Sociedade Brasileira de Psicologia Analítica
}

\begin{abstract}
Este artigo tece considerações quanto à possibilidade e ao alcance de grupos vivenciais, sob a perspectiva da Psicologia Analítica de Carl G. Jung, em nosso contexto socioeconômico atual. Há uma proposta prática de grupos de construção de máscaras e personagens, e a apresentação $e$ comentários das contribuições de diferentes autores que trazem conceitos junguianos clássicos para a dimensão grupal, consideram de maneira criativa o ritual, do ponto de vista psicológico, e questionam a viabilidade de trabalhos grupais. Numa abordagem mitológica, são considerados Górgona, Dioniso, Ártemis, Eco e Narciso, com destaque à deusa grega Héstia, cujas características são relacionadas a aspectos necessariamente presentes nos grupos vivenciais e à possibilidade de ocorrer uma experiência psicológica. Os grupos vivenciais são considerados favorecedores da perspectiva de alteridade, na medida em que cada participante tem neles a oportunidade de se afirmar e de ser confirmado, isto é, de se expressar e de refletir, num campo interacional fértil.
\end{abstract}

Descritores: Psicologia junguiana. Terapia de grupo de encontro. Psicologia do self. Mitologia.

\section{Grupos vivenciais sob uma perspectiva junguiana}

Psicologia encontra seu território num campo intermediário e frontei-
riço - nem físico, nem metafísico - onde é permitida e favorecida a

1 Docente do Instituto de Psicologia - USP. Avenida Professor Mello Moraes, 1721 CEP 05580-900, São Paulo, S. P. Telefone: (11) 3845-4526. Endereço eletrônico: lauvfrei@usp.br 
interação entre polaridades e a criação contínua de algo que podemos chamar de individualidade. É um local onde o uso do gerúndio parece extremamente pertinente, pois o que é psicológico acontece acontecendo, e o que se define e se cria como produto de um processo logo passa a ser matériaprima de uma nova criação. Nesse território, há mais a equilibração do que o equilíbrio, mais o processo de individuação do que a aquisição da individualidade.

Como fazer jus, em teoria e na prática, a esse campo na atualidade? E como situar a Psicologia neste vertiginoso início de milênio? Que referenciais podem norteá-la? E que propostas de intervenção comportam algum significado e encontram alcance prático efetivo?

Essa contribuição embasa-se na Psicologia Analítica de Carl G. Jung. Em pesquisa anterior (Freitas, 1988, 1991), caracterizei a psicoterapia como um rito atual de iniciação. Percorri seus antecedentes históricos e estabeleci tal relação a partir do fio norteador da vivência simbólica, que encontrei tanto em ritos iniciáticos quanto no trabalho com sonhos em processos psicoterápicos. Os relatos de sonhos forneceram-me exuberante material ilustrativo, a tal ponto que sugiro denominá-los sonhos iniciáticos.

A seguir, diante da escassez de ritos significativos em nossa sociedade atual, dediquei-me a explorar e desenvolver um trabalho psicológico grupal de construção de máscaras e personagens, tendo como conceitos centrais a persona e o processo de individuação. Conseqüentemente, pude constatar a importância e o potencial de grupos vivenciais (Freitas, 1990, 1995).

\section{Persona, Máscara e Grupos}

Dentre os conceitos básicos que Jung propôs para compreendermos a psique, a persona foi aquele a que ele menos se dedicou. Inicialmente, Jung (1934/1977) definiu-a como um segmento, mais ou menos arbitrário, da psique coletiva, desenvolvido com grande esforço e aparentando ser uma individualidade, mas constituindo apenas um compromisso entre o indivíduo 
e a sociedade, uma máscara superficial a ser removida para que o self, em toda sua exuberância, pudesse se revelar e, a consciência, se ampliar.

No entanto, urge reconhecer o potencial criativo da persona. É fato que ela pode ser rígida e impedir a vivência de certos símbolos. Além disso, é possível regredir a uma persona anterior em nossa vida, para evitar novos desafios. E todas as culturas possuem personas que podem colaborar mais para manter sua própria coesão do que para promover a individuação dos membros que as adotam (ou seriam por elas adotados?), como, por exemplo, do louco e do marginal.

Justamente por apresentar tantas possibilidades de desvio, estagnação e desperdício de seu potencial simbólico, a persona merece aprofundamento e especial consideração. Sugiro considerá-la como uma estrutura da personalidade, cuja função principal seja, a partir de sua expressividade, pôr-nos em relacionamento, propiciar-nos o encontro de uma maneira de ser e estar com os outros, sem precisarmos, para isso, abandonar nossa individualidade ou os símbolos operantes a cada momento. Junto à sombra, a persona pode propiciar a atualização do potencial da personalidade, além de ser confrontada pelo ego, tornando-se mais flexível ou mais adequada a cada situação vivida, além de, em si, oferecer-nos códigos culturais para a elaboração de símbolos na conduta e interação social.

A persona sempre tem um caráter múltiplo, pois necessitamos de várias máscaras para viver, em certo grau, e assim ela colabora para a apreensão e expressão da multiplicidade do self.

Ao veicular o que em nós já está pronto para assumir um canal de comunicação, ao buscar elementos no conjunto de papéis sociais oferecidos pela cultura, que propiciam maneiras de interação, articulando-se com o self de modo a colaborar com seu movimento de equilibração dinâmica e constante, a persona é coadjuvante indispensável no processo de individuação.

O melhor meio que encontrei para a exploração da persona foi desenvolver um trabalho de construção de máscaras e personagens, com recursos expressivos corporais, plásticos e dramáticos, no âmbito de grupos vivenciais. O grupo define uma totalidade que sugiro chamar de self grupal, ampli- 
ando o conceito junguiano de self individual, de maneira análoga à que fez Byington (1985) quando utilizou o termo self terapêutico.

Por outro lado, a relação entre persona e máscara é direta para o próprio Jung, podendo também ser identificada na linguagem coloquial e no campo das artes cênicas e das práticas ritualísticas religiosas.

Ao pesquisar a máscara em diferentes contextos históricos, depareime com um fenômeno universal e de alta complexidade, encontrado em todas as épocas e continentes, e com autores (Caillois, citado por Bril, 1983) que consideram seu aparecimento anterior ao da roda. A máscara apresentase como maneira de auto-representação, meio de comunicação com seres de outra realidade em cerimônias religiosas ou, ainda, como manifestação artística, forma de proteção, instrumento em rituais terapêuticos, funerários ou políticos. A máscara é sempre um agente de transformação, seja no sentido de cura, mudança de status na comunidade, ou de comunicação, exigindo que algo essencial se manifeste.

Ao buscar personagens da mitologia grega relacionados à máscara, encontrei três (Vernant, s.d.): em primeiro lugar, a Górgona, uma cabeçamáscara, terrível e ameaçadora, potência sobrenatural com poder de seduzir e petrificar, trazendo o sobrenatural, o pavor que é evocado e a necessidade de descobrir maneiras seguras de aproximação. Ártemis, a segunda divindade, inclui máscaras e mascaradas em seu culto. Considerada a senhora do mundo selvagem, vive em regiões pantanosas e fronteiriças, onde estabelece e zela por regras rígidas. Guardiã do limite entre o selvagem e o civilizado, conhece e promove a passagem do primeiro para o segundo, desempenhando importante papel nos rituais destinados a crianças e jovens, ao prepará-los para a sexualidade e para a cidadania, protegendo-os até o momento de sua plena integração social, sem deixar que se desarticulem o selvagem e o civilizado, tampouco que se invadam mutuamente. A terceira divindade grega associada à máscara é Dioniso, considerado o deus-máscara e o deus do teatro. Também associado ao vinho, às ilusões e aos estados alterados de consciência, é o responsável por trazer ao cotidiano rompantes do diferente e do inesperado, do vivenciado como caótico ou de outra natureza, constituin- 
do-se assim no deus da alteridade, e é considerado estrangeiro pelos gregos. Chama ao encontro olho-no-olho, quando ocorre uma transformação. A experiência dionisíaca, ao invés de nos integrar ao mundo, projeta-nos fora dele, eliminando barreiras entre o divino e o humano, o humano e o bestial, o aquém e o além, dissolvendo fixações e permitindo o desenrolar de processos.

Desenvolvi uma maneira de trabalhar com grupos vivenciais que constroem máscaras e personagens, numa série de encontros que tem como objetivo principal a exploração do potencial criativo da persona. Há várias etapas: uma etapa artesanal, em que se constrói uma máscara e um personagem; uma etapa dramática, em que se experimenta vivenciar e apresentar ao grupo o que foi criado, e uma etapa final, de elaboração verbal.

As consignas, inspiradas em trabalhos com imagens, no conceito junguiano de imaginação ativa e em elementos encontrados nas pesquisas sobre a máscara, são feitas com o intuito de deixar brotar imagens mobilizadoras que servirão ao processo de elaboração, tanto no âmbito individual quanto no grupal.

Alguns grupos são visitados pela Górgona: a máscara criada evoca algo pavoroso, a ser contatado e elaborado. A experiência dionisíaca, por sua vez, está sempre presente, levando ao encontro do diferente, da transformação e a um estado de consciência mais aberto, que incorpore o personagem. Com o toque dionisíaco, a experiência da máscara deixa de ser bidimensional, ganha plenitude, respiração, temperatura e movimento, permitindo a integração de algo novo.

E embora apóie e propicie a vivência, apenas Dioniso não basta. É necessário Ártemis, que contextualiza a experiência e permite as passagens, nos âmbitos grupal e intra-psíquico. Ela inspira consignas e favorece passagem extremamente difícil, de algo sombrio à consciência. Através das máscaras e personagens, permitimos a aspectos da sombra experimentarem certas personas, colocarem-se em comunicação e interação e serem integrados à consciência. 
São elucidativos também os mitos gregos de Eco e Narciso, que focalizam a questão da reflexão e da expressão em diferentes nuances e possibilidades. Eco, a ninfa que se esvai à beira do lago em que Narciso se observa fascinado, remete-nos à expressão, que pode ser repetitiva, estagnada e levar ao definhamento ou, por outro lado, trazer o contexto relacional e a dimensão erótica, de paixão, envolvimento e busca de comunicação. E Narciso, por sua vez, conduz-nos a um local onde a reflexão pode ser paralisada e paralisante ou, por outro lado, um meio de auto-conhecimento, busca de transcendência do ego e possível nascimento da linguagem.

Para que a persona possa exercer seu potencial criativo, é preciso cotejar expressão e reflexão, usando todos os recursos de que dispomos: o corpo e suas possibilidades simbólicas, o convívio e a interação, a capacidade de estruturação da consciência a partir das imagens e a possibilidade de linguagem oral, que inaugura um campo próprio e especialmente favorável à elaboração simbólica.

Coordenar um grupo vivencial implica encarregar-se do estabelecimento e manutenção de um campo interacional, no qual os símbolos possam se definir, apresentar, interagir e ser, em alguma medida, assimilados à consciência. Aspectos narcísicos da personalidade podem ter uma vivência dionisíaca, que lhes permita movimento, reconhecimento e interação. E aos aspectos ecoístas é dada a oportunidade de reflexão, experiência narcísica, e de conseqüente busca de expressão e comunicação mais eficazes.

Sendo a articulação entre persona e sombra constante e dinâmica, abre-se a possibilidade de trabalhos vivenciais em contextos não estritamente terapêuticos, mas pedagógicos. O trabalho em grupo permite inúmeras possibilidades, dependendo do objetivo proposto e do que se constele no campo interacional. Há uma oportunidade, compartilhada, de ensaiar personas, de pôr em movimento a totalidade psíquica e, quem sabe, de criar novas personas em nível social, no mínimo, a de participante de grupos vivenciais, o que dá certo suporte à personalidade para que, em outros contextos, explore novos meios de reflexão e expressão de seus próprios símbolos e dos que se apresentem no âmbito coletivo, em cada situação. 


\section{Grupos sob uma perspectiva junguiana?}

Ao percorrer as alusões de Jung ao tópico "grupo", no conjunto de sua obra, somos constantemente alertados pelo autor dos perigos de regressão, contágio ou intoxicação psíquica, criação de dependência mútua, perda de autonomia, massificação e fuga do confronto consigo próprio. Jung deixa claro que seu método de trabalho era a análise individual e não estimulava trabalhos em grupos.

No entanto, parece difícil compreender tal recusa num autor que enfatizou tanto a totalidade quanto a multiplicidade da vivência psíquica, a importância da interação entre polaridades e propôs, como pilares, os conceitos de processo de individuação e de inconsciente coletivo. De alguma maneira, o individual e o coletivo encontram-se estabelecidos em seu referencial teórico e, parece-me que, embora a individuação implique a ampliação e constante estruturação dinâmica da consciência, o indivíduo não é sinônimo de ou equivalente à consciência, e tampouco coletividade corresponde a inconsciente.

Whitmont (1974) estranha que Jung, com sua abrangente e complexa visão de ser humano, tenha considerado os grupos tão unilateralmente, identificando, muitas vezes, grupo e massa. Esse autor considera que explorar o inconsciente, em sua manifestação numa experiência grupal, é tão importante quanto experienciá-lo pela introversão através de sonhos ou imaginação ativa, e aponta as vantagens do que denomina "análise num setting grupal": o indivíduo sente que pertence a algo maior, pode experienciar tanto conformidade quanto singularidade, buscar auto-sustentação, conviver com uma ampla gama de tipologias e pontos de vista, vivenciar situações numa concretude maior e, além disso, amplia-se o trabalho com as projeções e as possibilidades de um relacionamento genuíno. Whitmont destaca que o arquétipo do grupo pode ser vivenciado tanto na dimensão que envolve sentir-se pertencendo, quanto na que implica valores e leis.

Em outra obra, Whitmont (1991) defende uma nova ética para a época atual, que valorize mais a experiência vivida do que preceitos pre- 
estabelecidos, assim como a retirada de projeções e considere também a perspectiva do outro. O autor defende uma aceitação acolhedora, que difere da resignação, e uma exploração lúdica sustentada por uma atitude de permanente busca, na qual a espontaneidade e a auto-disciplina coexistam, numa constante autodescoberta e aperfeiçoamento de relacionamentos baseados em confiança e aceitação mútuas, tanto individual quanto coletivamente. O entendimento intelectual continua a ser importante, mas não é suficiente; torna-se crucial uma avaliação afetiva, que inclua a dimensão concreta, corporal e de apoio recíproco.

Além das experiências de alegria, prazer e sucesso, as de medo, fracasso e destrutividade são valorizadas, não enquanto atuação, mas de maneira meditativa. Os aspectos da sombra, antes considerados vergonhosos, agora são vistos como equilibradores, na medida em que possuem um potencial transformador indispensável à vida psíquica. Passa a ser importante aceitar a realidade total de como somos e não apenas de como desejaríamos ser. Polaridades, aparentemente excludentes, passam a ser toleradas simultaneamente, numa busca de integração e inclusão. A vida é tomada nas dimensões de liberdade e responsabilidade, sendo legítimo alterar planos, improvisar, ensaiar novas soluções. O tempo, vivenciado não tanto como uma seqüência de períodos cronológicos mensuráveis de maneira objetiva, mas como único, presente e referenciado na percepção subjetiva, isto é, o tempo definido como kairós, passa a trazer o senso de oportunidade, de busca do momento adequado, e a função da intuição é valorizada.

Whitmont (1991) apresenta ainda um capítulo inteiro sobre o ritual, considerando-o um elemento importante, por promover contenção e aceitação, controle da intensidade emocional e redirecionamento de impulsos. Os rituais tradicionais, coletivos e definidos por passos preestabelecido, não funcionariam mais. Para ter eficácia psicológica, os rituais precisam ter significado, o que atualmente implica uma busca constante de coexistência de diferenças, tolerância e experimentação consciente, em vez de repressão. Desloca-se o foco do ego para o self e para a relação com o outro e com o grupo. 
Além de rituais que dêem conta da dinâmica intrapsíquica, como Neumann (1976) já apontara, são agora necessários rituais interpessoais e grupais, em que o elemento lúdico esteja presente. O jogo dramático é muito adequado, na opinião de Whitmont (1991), pois testa a realidade, apresenta regras definidas e também flexíveis, implica seriedade e comprometimento, cujo vínculo maior é com o prazer de jogar e não, vencer ou perder. Além disso, mobiliza e estrutura forças da personalidade, inter-relaciona a fantasia e a pragmaticidade, intercomunica os participantes e, finalmente, tem um efeito catártico. A vivência corporal também é fundamental, pois embasa o vivido na experiência, que transcende o conhecimento intelectual.

Tal enfoque é bastante coerente com o que Adams (2004) apresenta em seus estudos sobre o princípio da fantasia. A partir de Jung e de Hilmann, esse autor propõe considerarmos a fantasia, de valor, em si, irredutível, como a matriz criativa de tudo que possibilita o aperfeiçoamento de nossa humanidade, por ser ela quem constrói a realidade, e não o inverso, e, nessa construção, ocorrem também desconstruções (Derrida, 1973), isto é, a destruição e o questionamento de padrões fixados para que se abram novas possibilidades.

Whitmont (1991) sugere que elaboremos novos rituais para responder a questões como: “Quem sou? Como sou? O que me motiva? Quem é você e o que o motiva? O que desejamos? O que podemos tolerar?” na tentativa de descobrir que fantasias, medos e desejos estão presentes, não importando seu conteúdo moral ou estético.

Há, nessa proposta, uma relação com as lendas sobre a Távola Redonda e a busca do Graal, que atualmente têm inspirado práticas numa dimensão ética renovada, como por exemplo, os trabalhos grupais (Whitmont, 1991; Zinkin, 1998), além de fornecerem o padrão de uma postura de busca e constante questionamento.

O passo seguinte para Whitmont é realizar a encenação ritualística, isto é, simbólica e delimitada no espaço e no tempo, das imagens e emoções que tiverem emergido, visando a promover sua aceitação, tolerância e assimilação pela personalidade. É possível ainda inverterem-se os papéis, para 
proporcionar a experiência de ambos os pólos do conflito. Várias técnicas de psicodrama podem ser de grande valia nessa etapa.

Um dos objetivos é chegar a uma perspectiva mais realista a respeito de nós mesmos, integrar exigências inflexíveis e/ou aspectos muito relegados, aceitar nossas fraquezas e limitações e adotar uma postura menos passiva frente à própria vida.

A valorização do ritual é encontrada em Jung (1950/1980), em revisão de uma palestra de 1939, na qual afirma que a regressão psicológica no grupo é inevitável, mas que ela pode ser parcialmente neutralizada pelo ritual, que coloca no centro a experiência de algo sagrado, com que o indivíduo deve estabelecer uma relação de interesse e atenção.

Nesse mesmo texto, Jung faz algo raro em sua obra: destaca elementos positivos da vivência grupal, afirmando que ela pode conferir ao indivíduo coragem, apoio e dignidade. E, no prefácio ao livro de Toni Wolff (Jung, 1959/1974), comenta que o valor espiritual e moral de um grupo é avaliado pelo valor médio de seus membros individuais, sem, necessariamente, haver uma experiência regressiva e massificante do grupo.

Talvez o autor junguiano que mais tenha valorizado o trabalho psicológico em grupo seja Zinkin (1998). Formado em análise junguiana e em análise de grupo, trouxe para a Psicologia Analítica elementos de outras abordagens, sobretudo de Foulkes, que propõe uma análise do grupo pelo grupo, todos no papel de analistas e analisandos, incluindo o coordenador. Zinkin supõe no grupo um nível primordial, no qual estariam os arquétipos do inconsciente coletivo, e sugere a análise da transferência no aqui e agora, inspirando-se em psicanalistas como Bion.

Zinkin considera que a coletividade, mais do que ameaçar o indivíduo, cria a possibilidade de surgimento da individualidade, e deve existir primeiramente na cultura para que o indivíduo se configure em uma pessoa.

Sob a perspectiva junguiana, a consciência é tanto ameaçada de dissolução pelo inconsciente coletivo quanto é, por ele, nutrida. Como as duas afirmações não são encontradas no mesmo texto de Jung, sua compreensão torna-se mais difícil. Da mesma forma como quando define o arquétipo em 
seu aspecto formal como inato e não transmitido pela cultura, e, quanto ao conteúdo e à manifestação, como culturalmente determinado.

A tarefa da individuação não é apenas garantir a própria individualidade contra uma multidão que ameaça destruí-la, mas perceber que ninguém vive isolado e que a vida não tem sentido por si só. Seu significado deriva da coletividade, da qual cada um é parte, e Jung, ao propor o centro da personalidade como o self, que é muito maior do que o ego, enfatiza a dimensão coletiva.

Segundo Zinkin (1998), cada indivíduo é como um nó numa rede, que seria a matriz do grupo. A partir dessa analogia, propõe o conceito de inconsciente cultural, pois para ele, Jung não negligenciou a importância da cultura, embora tenha enfatizado mais o acultural em detrimento do papel da transmissão cultural. É importante não esquecer que os arquétipos se constituem e ganham forma em situações de interação, só tendendo a funcionar como entidades independentes e autônomas em casos patológicos, pois, em contextos compartilhados, sua função natural é facilitar a interação e a comunicação.

Para Zinkin, o relacionamento é primário e o indivíduo é uma realidade secundária. Desde o início da vida estamos em relação, e o mundo interno é uma construção que deriva da comunicação interpessoal. Temos de nos encontrar no diálogo com outras pessoas antes de poder dialogar conosco. Também na análise, individual ou grupal, a imagem de si próprio resulta da interação. O grupo é concebido como o ambiente natural em que o indivíduo se torna ele mesmo, assim como a planta que brota de um solo fértil.

Inspirado em Bion, Zinkin (1998), propõe que consideremos o grupo tanto como continente quanto como conteúdo. Inicialmente é o terapeuta que cuida do setting e, portanto, do continente grupal, para que ele seja seguro e acolhedor e altera-o nos momentos em que avalie como potencialmente terapêuticas a novidade ou a surpresa. Mas o próprio grupo pode ser responsável por sua qualidade de continência, podendo promover mudanças significativas. Quando os membros mudam, muda o grupo em que estão, o que, por sua vez, lhes permite mudar ainda mais. Há uma interação circular entre 
continente e conteúdo: o grupo e seus participantes são como sistemas em constante equilibração.

Quando os participantes falam do “grupo”, instaura-se uma ambigüidade e não se sabe mais se eles são o grupo, os conteúdos do grupo ou o continente do grupo. No entanto, ressalta Zinkin (1998), tal confusão pode ser muito criativa, gerando movimento, mudanças e tomada de consciência. É impossível separar uma pessoa de seu continente.

Esse mesmo autor recorre a Martin Buber para melhor caracterizar a interação no contexto analítico, alegando que Jung, na maioria de seus escritos, favoreceu a dimensão intrapsíquica e o diálogo da consciência com o inconsciente, em detrimento da relação interpessoal. Buber, em resposta a Carl Rogers (Zinkin, 1998, p. 200), teria enfatizado que não basta mostrar aceitação do outro, afirmando-o, mas que é também preciso manifestar-se contra ele, confirmando-o. Em outras palavras, não seria suficiente ser nãodiretivo e deixar claro que se entende o que o paciente está expressando, como propõe Rogers. Para Buber, também é necessário comunicar que o entendimento se dá sob a perspectiva de uma outra pessoa. Na possibilidade de percepção dessa qualidade é que estaria o valor maior da interpretação, e não em seu conteúdo.

Assim, o diálogo é concebido como um princípio conciliador e a relação mostra que há dois sujeitos, em interação, e o senso de self de cada um é favorecido precisamente por sua incompletude sem o outro. O sujeito é descentrado, mas não eliminado. Aceitação mútua não significa concordância, mas aceitação das diferenças, e a partir dela cada um poderá afirmar e confirmar o outro, e ambos beneficiam-se com a troca.

O potencial criativo da vivência, assim como o da multiplicação de diálogos e interações assim concebidos, talvez seja a maior vantagem dos grupos vivenciais. Afirmar e confirmar relacionam-se com a expressão e reflexão aludidas acima, quando foram comentados os mitos de Eco e Narciso. E, segundo Zinkin (1998), é o diálogo assim concebido que permite aproximar a análise individual da grupal, propondo, numa espécie de subversão, a primeira como um caso particular da segunda. 
Para continuar fertilizando o solo que fundamenta trabalhos grupais sob uma perspectiva junguiana, passo a uma abordagem mitológica mais explícita. Embora não exponha exatamente como solucionar problemas, ao evocar mais imagens e emoções do que expressar uma lógica discursiva ou um enredo coerente, o mito nos coloca em contato com o potencial arquetípico e cultural, mobilizando nossa criatividade tanto no nível individual quanto coletivo.

\section{Héstia e os grupos vivenciais}

Para Hillman (1998) os mitos expressam melhor do que as teorias o que acontece na análise, e ele busca mitos complementares aos tradicionalmente relacionados a ela, como Eros e Psiquê, Apolo e Dioniso, Atena, Édipo ou os que seguem o paradigma mãe-bebê. Ele propõe, junto com outros autores que serão citados abaixo, que consideremos Héstia, a deusa grega que enfatiza a interioridade e o anonimato.

Acrescento que é possível esboçar relações entre Héstia e a experiência nos grupos vivenciais e espero também proporcionar algo de seu clima emocional, além de valorizar um arquétipo que é bastante relegado ao esquecimento em nossa cultura.

Héstia estava entre os doze primeiros deuses do Olimpo, tendo vivido antes o período em que seu pai, Cronos, temia ser suplantado por um de seus filhos e, para evitá-lo, engolia cada um deles ao nascer. Ela, a primogênita, foi a primeira a ser engolida e a última a ser expelida quando Zeus conseguiu banir Cronos e inaugurar a era olímpica (Brandão, 1987).

Trata-se de uma deusa sem imagem, comumente representada apenas por um círculo ou uma chama crepitante. Ela não sai em aventuras pelo mundo, mas permanece ao redor da lareira, que mantém acesa. Seu espaço é redondo, quente e acolhedor, no qual se pode devanear sem se perder, seguindo o movimento das fagulhas ou da crepitação do fogo, num estado contemplativo, aquietado. Imagens, idéias e sensações acabam surgindo e 
nos convidam a olhar para elas até que uma ganhe nitidez e se apresente com mais insistência.

Héstia relaciona-se com o focalizar: um processo dinâmico que recorta e destaca algo, que procura iluminar uma parte do todo, chamando a atenção para sua especificidade, sem perder a situação global. Focalizar, condição tanto para a percepção quanto para a imaginação, permite que passemos de uma a outra e possibilita a criação e vivência de um campo emocional onde elas coexistam (Kirskey, 1992).

Héstia traz calor. Aquece e, ao fazê-lo envolve, protege, acolhe e apazigua. Traz conforto ao corpo, que pode ficar à vontade e descontraído (Castillejo, 1973). Cria um clima de sossego e confiança, permitindo uma atitude aberta para o novo, que poderá apresentar-se; caso contrário, será ocasião de rememorar o antigo, o realizado, contemplar, compartilhar, alojar e alocar idéias e sensações, tecendo a própria história e memória, retomando inúmeras vezes as mesmas imagens, num exercício de focalização dinâmica.

O trabalho com grupos vivenciais consiste na criação de um campo interacional específico, no qual se relacionam forças dinâmicas que põem em contato todos os participantes e, simultaneamente, encarregam-se do estabelecimento de uma coesão tal, que considero possível e pertinente propor os conceitos de consciência grupal, sombra grupal e símbolos grupais. É o campo simbólico constelado que acolhe e conduz ao conceito de self grupal, algo intrinsicamente associado a Héstia: lugar, num sentido que transcende o físico, de repouso, acolhimento, interação, pertinência, devaneio, criação de sentido, meditação e surgimento de imagens. O verbo preponderante é “estar": mais do que fazer ou ser algo, basta estar e deixar que as coisas aconteçam.

Héstia cria, numa simples construção, um clima emocional de fraternidade em torno de um fogo comunitário, tanto na esfera doméstica e íntima quanto na pública, dos banquetes e festas. Héstia diz respeito tanto à casa quanto à cidade.

Héstia é, sobretudo a casa, o lar, lugar de repouso, reabastecimento, intimidade e apropriação da identidade. Lugar também de congregação, refeição, encontro, festejo. O espaço torna-se ambiente psicológico, ganha 
alma, passando a constituir o palco para a interação e harmonização de forças díspares e dinâmicas. Muitas vezes percebida como o próprio lugar, Héstia congrega as pessoas e possibilita uma experiência anímica, um local vivo, onde há comunidade e comunhão. Ela nos permite transformar uma casa em um lar, uma cidade em um espaço vivo.

É interessante observar a relação do grupo com o espaço em que se dão os encontros. Há uma interação dinâmica, caracterizada por exploração, conquista e apropriação. As características espaciais têm uma força estruturante no grupo, na medida em que colaboram com a organização das interações, possibilitando aproximações e afastamentos entre os participantes e deles com o material expressivo e as produções realizadas, a cada momento. Achar o próprio lugar passa a ser um desafio em cada situação vivenciada no grupo.

O espaço costuma adquirir características ligadas ao ritual, que podemos associar ao temenos, o espaço sagrado do mundo grego: geralmente, na sala, há o canto do compartilhar grupal, os lugares de reflexão e criação individual, os locais para armazenamento e exposição do material criado. Almofadas, pedaços de fita crepe colados ao chão, luzes, acesas ou apagadas, são elementos que ajudam a transformação do espaço físico em um ambiente psicológico.

Héstia também tem a qualidade de ser um espaço centralizado, remetendo ao fogo, ao altar, à lareira, à cidade, à Grécia, à Terra e ao universo. No corpo, ela é associada ao coração. A própria idéia de centro é controversa, sendo impossível imaginar, em nossa natureza complexa, multifacetada e em permanente movimento, um centro fixo, local de harmonia, equilíbrio e saúde. A deusa não parece se abalar com isto. $\mathrm{O}$ centro que nos oferece é aquele que organiza um espaço, redondo, simultaneamente centrífugo e centrípeto, de onde se irradiam luz e calor e todo um campo simbólico pode ser definido, dando continência a aspectos diferentes que, em outros contextos, poderiam ser contraditórios ou mesmo patológicos.

A deusa nos faz também considerar os afazeres domésticos, que geralmente são monótonos e repetitivos, enxergando o quanto são estruturais, 
necessários e indispensáveis e fornecem uma base sólida, podendo ser realizados não com ênfase no aspecto de obrigação, mas no da meditação que favorecem, justamente por sua insossa repetição, ao permitirem à consciência devanear e acolher novas imagens.

Nos grupos de criação de máscaras e personagens, nas etapas que envolvem tarefas manuais trabalhosas, cansativas e repetitivas, muitas vezes ocorrem importantes insights grupais ou aparecem símbolos a serem acolhidos e trabalhados pelo self grupal.

Héstia permite o estado de moradia. Sem ela, vivemos perambulação, frio, escuridão, desvio, delírio. Nossa linguagem utiliza metáforas espaciais para tais estados quando alude a estarmos "fora de centro", “deslocados”, “desfocados”, “sem chão”, “sem lugar” (Kirskey, 1992).

Héstia é anfitriã afável. Provê hospitalidade, reunindo todos à volta da lareira. E, se necessário, é capaz de prover também hospitalização, pois dores, cicatrizes e sintomas também podem ser iluminados, focalizados e aconchegados, para que então possam se movimentar, reagrupar, re-significar e aquecer (Kirskey, 1992).

Héstia permite-nos habitar o espaço psicológico para transformar nossos restos fantasmagóricos, imagens que se recusam a receber um foco, em imagens que possam ser acolhidas e hospedadas.

A utilização de recursos expressivos tem-se mostrado de grande valia para a emergência de imagens numa forma mais precisa e contextualizada. Desde que não se façam consignas muito restritivas, há uma exploração espontânea do recurso e do material, que favorece a definição do que está pronto para ser trabalhado e ocupar o lugar de "figura" para a consciência, e do que servirá como “fundo”, num dinâmico processo de focalização, a cada momento ou etapa do processo do self grupal.

Viver uma crise, freqüentemente, pode ser entendido como tentar um novo ajuste de foco, uma mudança de perspectiva ou o ensaio de uma maneira de destacar aspectos diferentes, num movimento para aproveitar a oportunidade de mudança e ampliar a consciência. Diferentemente de um delírio dionisíaco, de uma viagem ao estilo de Hermes, ou de uma fuga a um 
ataque de Pan, Héstia provoca abalos que nos fazem tomar outro ponto de vista ou outra perspectiva, levando-nos a uma significativa mudança de foco, e favorece a entrada de novas imagens no campo da consciência.

Em um grupo vivencial, podemos oferecer diferentes linguagens para a expressão dos símbolos, como, por exemplo, desenho, modelagem, palavras, gestualidade, os quais podem encontrar a melhor forma de se apresentar à consciência. Não há regras a priori. O coordenador cuida da manutenção de um campo fértil para a vivência do self grupal, põe-se, tal como Héstia, à espera do que emergirá e coloca-se no foco da consciência grupal.

Segundo a mitologia grega, Héstia nunca se apaixonou, permanecendo virgem e intocada por Eros ou Afrodite. Poseidon e Apolo manifestaram intenção de se casar com ela, mas Héstia foi a Zeus pedir proteção, oferecendo em troca seu voto de castidade. Foi, por ele, aceita e colocada no centro do Olimpo e da casa, onde se destaca por ser a primeira a receber homenagem e ser-lhe oferecida a melhor parte dos sacrifícios. Posteriormente, cedeu seu lugar a Dioniso (Harding, 1985).

No trabalho com grupos vivenciais, é importante que o coordenador, inspirado por Héstia, não ceda aos assédios de Apolo e Poseidon. O primeiro tende a impor uma precoce compreensão intelectual, racional e lógica à experiência vivida, quando ainda é necessário permanecer mais tempo na vivência íntima e silenciosa. E Poseidon inclina à inundação por sentimentos ou conteúdos inconscientes, de tal maneira que põe em risco a experiência de centração e objetividade. Atividades de relaxamento, busca de centro, expressão não-verbal e reflexão tranqüila, muitas vezes, protegem o grupo e cada participante de tais assaltos intempestivos.

A própria virgindade de Héstia parece auferir-lhe as qualidades de estabilidade e coerência. Ela é capaz de guardar e proteger as imagens que possibilita existirem, permanecendo nos bastidores, anônima.

O lugar da casa onde o fogo permanecia aceso era muito bem cuidado e até venerado. A família se reunia ao redor da lareira e, além de fornecer calor e iluminação, o fogo também era usado para o preparo de alimentos. Quando um dos membros partia para formar outra família, levava um pouco 
daquele fogo dos pais, simbolizando a continuidade familiar e a criação de um novo centro. Outro ritual significativo ao redor do fogo de Héstia consistia em ali apresentar à comunidade a criança que completava cinco dias de vida (Bolen, 1990).

Cada cidade tinha sua lareira comunal, na qual o fogo público era mantido e Héstia era reverenciada. Os templos de Héstia tinham sempre uma forma circular e seu fogo era também usado em sacrifícios. As cerimônias eram simples e sem sangue, valendo-se apenas do fogo da lareira e da água pura, que era despejada num vaso de cerâmica, cuja conformação não lhe permitia permanecer em pé - a atenção constante e cuidadosa é fundamental para o desempenho das tarefas associadas ao culto de Héstia.

A deusa nunca se casou, nunca engravidou, mas é uma mãe dedicada. Remete, talvez, ao que de mais essencial podemos conceber quanto ao arquétipo da Grande Mãe, àquilo que garante as bases do amor e da capacidade de manter o lar unido, a maternagem que independe da concepção e da dimensão corporal e onde o filho é o principal foco das atenções. Pode aludir também a uma maternidade idealizada. Do ponto de vista intrapsíquico, quem se relaciona satisfatoriamente com as características desse arquétipo é capaz de se cuidar bem, além de, por exemplo, viver sozinho sem se sentir desamparado.

As vestais, sacerdotisas de Héstia, eram recolhidas ao templo entre 6 e 7 anos de idade, e lá permaneciam por trinta anos. Mantinham-se anônimas e faziam votos de castidade absoluta, sob risco de serem enterradas vivas. Eram também duramente punidas se deixassem o fogo se extinguir. Nos templos, sua inocência era oferecida como compensação às faltas dos homens, garantindo-lhes êxito e proteção.

O tempo associado a Héstia não é o do relógio, do calendário ou dos prazos, aquele que delimita tarefas a cumprir. Ela permanece absorta no que faz, sem pressa, muito mais envolvida pelo tempo do que desafiada por ele. Essa deusa tem mais afinidade com o tempo kairós do que com o cronológico. Quando regidos por Héstia, é freqüente perdermos a noção do tempo, numa experiência que pode ser nutritiva e apaziguadora de tensões. 
Héstia permanece oculta, em silencioso autodesenvolvimento. Seu conhecimento mantém-se restrito à intimidade, sem necessitar de reconhecimento público. Remete a aspectos da vida que são velados, mas não pedem desvelamento, possuindo uma ética própria (Demetrakopoulos, 1987).

A não-personificação da deusa também faz pensar na postura do coordenador do grupo: cuida das condições para a criação e manutenção de um campo simbólico, acolhe e protege o que ali se apresenta, mais do que dirige, opina ou procura viver relacionamentos humanos. Ele, paradoxalmente, é quase ninguém e tem uma presença fundamental, ao possibilitar o espaço para a experiência psicológica se dar, para as imagens se apresentarem e serem focalizadas.

Apenas uma vez, na literatura, Héstia é associada intimamente a algum outro deus. Trata-se de Hermes, deus fálico, protetor da fertilidade da família e desencadeador de boa sorte, também solitário, simbolizando a fonte da vida em seu aspecto dinâmico e ativo (Demetrakopoulos, 1987). O par Hermes-Héstia compartilha a criação de um tipo de fogo mais do que interage pela sexualidade; usufrui do calor da proximidade mais do que do ardor.

Estar bem com Héstia é ter para onde voltar, poder retornar à raiz, seja casa, família ou nação. A solidão para Héstia é uma contingência ou mesmo uma opção, não um problema como no caso da criança abandonada ou do puer desorientado pelo mundo.

O self grupal é como uma casa à qual se retorna para compartilhar as atividades e incursões realizadas no mundo. Boa parte do que se faz em grupos vivenciais é focalizar, acolher e expressar imagens significativas. Outro tanto consiste em interagir com elas: associar, relacioná-las entre si ou ao ego. Exercícios de imaginação ativa também podem ser realizados. E compartilhar com os outros participantes o que se está vivenciando é um componente fundamental. A acolhida, seja com simpatia, indiferença ou estranhamento, costuma trazer o sentido de retorno ao lar, pois o novo é apresentado e relacionado com o que já foi compartilhado e compõe a história do grupo, passando assim a pertencer ao imaginário e ao acervo simbólico do self gru- 
pal. Aqui observamos novamente a importância do fato de ter onde e com quem se expressar e refletir, isto é, poder ser afirmado e confirmado.

A técnica junguiana de amplificação, que consiste em remeter o símbolo emergente a um material da cultura com conteúdo análogo, pode ser entendida como um tipo de focalização no qual a imagem é o centro de onde saem e para onde novamente convergirão todos os movimentos da consciência.

Ao redor do fogão, os acontecimentos são comentados e também se fazem as pazes e se perdoa. Héstia dá um sentido de unidade e integração a toda a humanidade. Calor humano, acolhimento, empatia, solidariedade, convívio são seus valores.

Hillman (1998) comenta que essa deusa escapa à divisão radical entre “dentro" e "fora”. Ela é totalmente interior, de dentro, e é também coletiva, o centro da cidade. Vida doméstica e vida pública se articulam e interpenetram graças a Héstia, para quem cidade e lar não são dissociados, insight psicológico e atividade pública não se antagonizam, e tampouco self e comunidade.

Héstia parece associar-se à possibilidade de uma experiência psicológica acontecer. Aconchego, tranqüilidade, calor, centralização, foco, nutrição, quietude e mobilidade são condições básicas, que permitem o surgimento de imagens e sensações, reflexões e trocas. Kirskey (1992) afirma que, graças a Héstia, despertamos psicologicamente e nossa "alma pode sonhar em paz”.

Sem Héstia, as imagens não podem se apresentar à consciência; a fantasia fica inibida e a vida psicológica torna-se seriamente comprometida. O pensamento conceitual não é capaz de prover as qualidades de Héstia, pois falta-lhe intimidade, subjetividade, individualidade e calor. Sem ela, tudo é vivenciado como fugaz e transitório. Sentimo-nos pequenininhos e insignificantes no mundo. Passamos frio. Ocorrem movimentos de ida mas não de volta, de retorno, de reabastecimento. Héstia garante o equilíbrio entre a circularidade e a linearidade, permitindo-nos viver movimentos espiralados, que melhor caracterizam os processos psíquicos: passar e ultrapassar deter- 
minado ponto, mas posteriormente a ele retornar, num nível mais ampliado de consciência, tecendo o fio da própria vida.

O grupo vivencial tem essa qualidade de possibilitar a dimensão psicológica em si, na medida em que é o próprio campo interacional em que ocorre a experiência.

\section{Considerações finais}

De acordo com a perspectiva simbólica aqui adotada para a consideração dos grupos vivenciais, há um fio condutor, responsável pelas “tecelagens” mais diversas, e muitas vezes, não-convencionais, mas que são consistentes e percorrem o caminho da individuação, ao mesmo tempo procurando-o e, ao assim fazê-lo, construindo-o. Esse fio é o símbolo, que permite a dimensão vivencial, envolve a personalidade total, abrange sempre suas dimensões racionais e irracionais e não deixa escapar a tonalidade afetiva e emocional do que quer que esteja sendo vivido. E não menos importante é a consideração do self relacional, seja ele individual ou grupal, terapêutico ou pedagógico, pois tais vivências se dão sempre em campos interacionais, isto é, na rede de relações transferenciais e compartilhadas.

Jung falava na constelação de um arquétipo, que levaria à formação de símbolos que seriam enraizados nele em cada situação vivida específica. Hoje, usa-se muito o termo configuração. Ambos expressam a consideração de algo embasador, não fixo, mas passível de mudanças, constantemente criado e recriado, e necessariamente contextualizado.

O arquétipo é universal, atemporal e a-espacial. É tão absoluto que se torna inapreensível, torna-se um pressuposto. O símbolo, que é sempre enraizado num arquétipo, é histórico, isto é, sempre se apresenta num meio específico, a uma consciência específica, seja ela individual ou grupal, num determinado momento e local. Ele não pode ser considerado independentemente do arquétipo que lhe serve de raiz; por outro lado, tampouco pode ser recortado da situação em que se apresenta. Dá-se no presente, mediador 
tanto da consciência com o inconsciente quanto do indivíduo com seu meio, nunca tendo um significado fixo, mas sempre necessitando do estabelecimento de relações e do reconhecimento das associações a ele. Seu sentido vai-se definindo dessa maneira, que é sobretudo vivencial, pois demanda a personalidade inteira e acontece num campo interacional, o self mais amplo.

Hillman (1998) comenta que estamos caminhando para uma hipertrofia de Hermes, em que o espaço cibernético, os cd-roms, telefones celulares e realidades virtuais oferecem-nos, a qualquer momento, inúmeras possibilidades de conexão com o "lá fora”. Para compensar tal desequilíbrio, necessitamos, talvez mais do que nunca, da qualidade centralizadora, intimista e circular de Héstia, que permite habitar nosso corpo, nosso tempo, nosso espaço, nossa interioridade, nossos significados, nossa história.

Nos grupos vivenciais, ela é privilegiada, pois tanto pode acolher cada participante quanto ser acolhida, permitindo-nos usufruir de seu calor e de sua capacidade de focalizar imagens e, sobretudo, possibilitar que experiências psicológicas aconteçam.

Freitas, L. V. (2005). Experiential groups according to a Jungian approach. Psicologia USP, 16 (3), 45-69.

Abstract: This article considers the possibility and the value of experiential
groups according to the perspective of Jungian analytical psychology in our
present socio-cultural context. It outlines a practical purpose of groups
involving the creation of masks and personages, and presents different
authors' contributions which take in a creative way the ritual under a
psychological viewpoint and question the viability of group works. It also
offers a mythological approach which comments the Gorgona, Dioniso,
Artemis, Echo and Narcissus, and emphasizes the Greek goddess Hestia,
her characteristics being related to aspects that are necessarily present in the
experiential groups and to the possibility itself of something psychological
to happen. The experiential groups are seen as promoters of alterity in the 
relationships, as each participant has the opportunity to assert himself and to be confirmed, of expression and reflexion, in a fruitful interactional field.

Index Terms: Junguian psychology. Encounter group therapy. Self psychology. Mythology.

Freitas, L. V. (2005). Groupes d'éssai pratique au regard de la psychologie junguienne. Psicologia USP, 16 (3), 45-69.

Résumé : Sur cet article on trouvera des considérations sur la possibilité et la portée de groupes d'essai pratique au regard de la psychologie analytique de Carl G. Jung, dans notre contexte social économique actuel. L'article ébauche une proposition pratique de groupes de construction de masques et de personnages; il présente et commente les contributions de différents auteurs qui transposent des concepts junguiens classiques à la dimension de groupe, qui considèrent de manière innovatrice le rituel du point de vue psychologique et qui s'interrogent sur la viabilité de travaux en groupe. Il offre en plus un point de vue mythologique où sont analysés Gorgone, Dionysos, Artémis, Écho et Narcisse et met en évidence la déesse grecque Hestia, faisant une relation entre ses caractéristiques et les aspects nécessairement présents dans les groupes d'essais pratiques ainsi que la possibilité qu'une expérience psychologique s'accomplisse. Ces groupes sont considérés comme favorisant la perspective de l'altérité, dans la mesure où chaque participant a l'occasion de s'affirmer et d'être confirmé, c'est-àdire, la possibilité d'expression et de réflexion, dans un contexte d'interaction fertile.

Mots clés: Psychologie jungienne. Groupes d'Essai Pratique. Psychologie du self. Mythologie. 


\section{Laura Villares de Freitas}

\section{Referências}

Adams, M. V. (2004). The fantasy principle - psychoanalysis of the imagination. New York: Brunner Routledge.

Bolen, J. S. (1990). As deusas e a mulher. São Paulo: Paulinas.

Brandão, J. S. (1987). Mitologia grega. Petrópolis, RJ: Vozes.

Bril, J. (1983). Le masque ou le père ambigu. Paris: Payot.

Byington, C. (1985). O conceito de self terapêutico e a interação da transferência defensiva e da transferência criativa no quaternio transferencial. Revista Junguiana, 3, 5-18.

Castillejo, I. C. (1973). Knowing woman. New York: Putnam’s.

Demetrakopoulos, S. A. (1987). Héstia, deusa do lar - um arquétipo oprimido. Revista Junguiana, 5, 127-142.

Derrida, J. (1973). Gramatologia. São Paulo: Perspectiva.

Freitas, L. V. (1988). A psicoterapia: um rito moderno de iniciação. Boletim de Psicologia,38(88/89), 9-20.

Freitas, L. V. (1990). O arquétipo do mestre-aprendiz - considerações sobre a vivência. Revista Junguiana, 8, 72-99.

Freitas, L. V. (1991). Sonhos iniciais e sonhos iniciáticos. Revista Junguiana, 9, 42-55.

Freitas, L. V. (1995). A máscara e a palavra: exploração da persona em grupos vivenciais. Tese de Doutorado, Instituto de Psicologia, Universidade de São Paulo, São Paulo.

Harding, E. (1985). Os mistérios da mulher. São Paulo: Paulinas.

Hillman, J. (1998). In. Spring 63, 9-21.

Jung, C. G. (1977). The relations between the ego and the unconscious. In C. G. Jung, The collected works (Vol. 7, pp. 119-292). London: Routledge and Kegan Paul. (Trabalho original publicado em 1934)

Jung, C. G. (1980). Concerning rebirth. In C. G. Jung, The collected works (Vol. 9-I, pp. 111-147). London: Routledge and Kegan Paul. (Trabalho original publicado em 1950)

Jung, C. G. (1974). Introduction to Toni Wolff's studies in jungian sychology. In C. G. Jung, The collected works (Vol. 10, pp. 469-476). London: Routledge and Kegan Paul. (Trabalho original publicado em 1959) 


\section{Grupos Vivenciais sob uma Perspectiva Junguiana}

Kirskey, B. (1992). Héstia: um fundamento de enfoque psicológico. In J. Hillman, Encarando os deuses (pp. 119-133 ). São Paulo: Cultrix.

Neumann, E. (1976). On the psychological meaning of ritual. Quadrant, 9(2), 5-34.

Vernant, J. P. (s.d.). Figuras, ídolos, máscaras. Lisboa: Teorema.

Whitmont, E. (1974). Analysis in a group setting, Quadrant, 16, 5-25.

Whitmont, E. (1991). O retorno da deusa. São Paulo: Summus.

Zinkin, L. (1998). Dialogue in the analytic setting. London: Jessica Kingsley.

Recebido em: 8.12.2004

Revisto em: 3.06.2005

Aceito em: 20.08.2005 